\title{
Critical care triage during the COVID-19 pandemic in South Africa: A constitutional imperative!
}

B M Morrow, ${ }^{1}$ PhD, PG Dip Health Res Ethics, PG Dip Pall Care Med, BSc Physio; P D Gopalan, ${ }^{2}$ MB ChB, FCA (SA) (Critical Care), PhD; I Joubert, ${ }^{3} \mathrm{MB}$ ChB, FCA (SA) (Critical Care); F Paruk, ${ }^{4} \mathrm{MB}$ ChB, FCOG (SA) (Critical Care), PhD; A Pope, ${ }^{5}$ BA LLB, PG Dip Int Res Ethics

${ }^{1}$ Department of Paediatrics and Child Health, Faculty of Health Sciences, University of Cape Town, South Africa

${ }^{2}$ Discipline of Anaesthesiology and Critical Care, Nelson R Mandela School of Medicine, College of Health Sciences, University of KwaZulu-Natal, Durban, South Africa

${ }^{3}$ Department of Anaesthesia and Peri-operative Medicine, Faculty of Health Sciences, University of Cape Town and Groote Schuur Hospital, Cape Town, South Africa

${ }^{4}$ Department of Critical Care, Faculty of Health Sciences, University of Pretoria, South Africa

${ }^{5}$ Emeritus Associate Professor, Private Law Department, Faculty of Law, University of Cape Town, South Africa

Corresponding author: B M Morrow (brenda.morrow@uct.ac.za)

\begin{abstract}
Triage and rationing of scarce intensive care unit (ICU) resources are an unavoidable necessity. In routine circumstances, ICU triage is premised on the best interests of an individual patient; however, when increased demand exceeds capacity, as during an infectious disease outbreak, healthcare providers need to make difficult decisions to benefit the broader community while still respecting individual interests. We are currently living through an unprecedented period, with South Africa (SA) facing the challenges of the global COVID-19 pandemic. The Critical Care Society of Southern Africa (CCSSA) expedited the development of a triage guidance document to inform the appropriate and fair use of scarce ICU resources during this pandemic. Triage decision-making is based on the clinical odds of a positive ICU outcome, balanced against the risk of mortality and longer-term morbidity affecting quality of life. Factors such as age and comorbid conditions are considered for their potential impact on clinical outcome, but are never the sole criteria for denying ICU-level care. Arbitrary, unfair discrimination is never condoned. The CCSSA COVID-19 triage guideline is aligned with SA law and international ethical standards, and upholds respect for all persons. The Bill of Rights, however, does not mandate the level of care enshrined in the constitutional right to healthcare. ICU admission is not always appropriate, available or feasible for every person suffering critical illness or injury; however, everyone has the right to receive appropriate healthcare at another level. If ICU resources are used for people who do not stand to benefit, this effectively denies others access to potentially life-saving healthcare. Appropriate triaging can therefore be considered a constitutional imperative.
\end{abstract}

S Afr Med J 2020;110(12):1176-1179. https://doi.org/10.7196/SAMJ.2020.v110i12.15411

The World Health Organization declared COVID-19 a global pandemic in March 2020. Shortly thereafter, the President of South Africa (SA), Mr Cyril Ramaphosa, declared a National State of Disaster and the country entered a state of lockdown, initially justified as necessary to prepare the healthcare system for the expected surge in numbers of seriously ill people infected by SARS-CoV-2. In April 2020, estimates were that SA would need up to 35000 intensive care unit (ICU) beds during the predicted COVID-19 pandemic peak. At that stage, fewer than 2500 ICU beds were allocated to the COVID19 crisis, with fewer than an estimated 5000 ICU beds in total being available across the country, based on previous national audits. ${ }^{[1,2]}$ In May 2020, the President conceded that the shortage of ICU beds was the 'greatest need' in the government's fight against COVID-19. ${ }^{[3]}$ This was the background against which the Critical Care Society of Southern Africa (CCSSA) rapidly developed a consensus guidance document (hereafter referred to as the CCSSA COVID-19 triage document) to inform the fair and appropriate allocation of scarce critical care resources during the pandemic. ${ }^{[4]}$ These pandemic triage recommendations were intended to be implemented only if critical care capacity became overwhelmed, despite all appropriate measures having been taken to increase surge capacity, as previously recommended. ${ }^{[4,5]}$ Owing to the rapidly progressive nature and scale of the pandemic, there was insufficient time to engage with all stakeholders usually involved in the development of clinical guidelines. However, the CCSSA COVID-19 triage document was purposively published online as a 'living' document. Three revisions to date based on public feedback have appeared. ${ }^{[4]}$ While the CCSSA welcomes constructive feedback and criticism to improve the triage guidance for SA ICUs, the article by Erasmus ${ }^{[6]}$ published in this issue of the SAMJ warrants some comments aimed at clarification and correction of misperceptions.

\section{Ethical considerations}

Triage and rationing of ICU resources are an unavoidable necessity. It is a sad truth that, at the best of times across the world, particularly in low- and middle-income countries, insufficient ICU beds, expertise and associated technology (including ventilators) are available for the population suffering from critical illness and injury. ${ }^{[7]}$ The situation in SA is no different: previous audits demonstrated a total of approximately 4700 ICU beds for the whole country, ${ }^{[1]}$ and a pre-COVID-19 assessment estimated a bed/population ratio of approximately 8,9:100 $000 .{ }^{[7]}$ The majority of ICU beds (75\%) are in private facilities that are inaccessible to most patients requiring ICU care, and furthermore some provinces have no critical care services at all. ${ }^{[1,2]}$ Consequently, the Critical Care Society of Southern Africa Consensus Guideline on ICU Triage and Rationing (ConICTri) was 
developed and published in 2019 to inform day-to day triage and ICU rationing as well as to guide administrators and inform the public about appropriate triage decision-making. ${ }^{[8]}$

In routine circumstances, ICU triage is premised on the best interests of an individual patient, including the likelihood of benefit from ICU treatment $v$. the potential for more harm when invasive ICU treatment is provided. Intensive care management is certainly not always in a patient's best interests. This balancing speaks to the ethical principles of beneficence (doing good) and nonmaleficence (avoiding harm), which are among the fundamental ethical considerations for triage decisions. ${ }^{[8]}$ For example, many patients with incurable life-limiting conditions would benefit far more from a palliative care approach, aimed at managing distressing symptoms and maintaining an acceptable quality of life. Providing a scarce resource such as ICU care to patients who are unlikely to benefit in the short or longer term prevents this care being given to those who have a good chance of benefiting. ${ }^{[8]}$ Appropriate triaging therefore assists to give effect to the right to access healthcare in resource-constrained circumstances. In other words, implementing triage measures can be considered a constitutional imperative.

In the case of a widespread increase in demand for ICU beds, as was predicted would occur in SA during the COVID-19 pandemic, and limited potential to increase critical care resources sufficiently, routine triage criteria had to be reconsidered. ${ }^{[9]}$ The balance of underpinning ethical considerations for disaster triage changes from focusing on the individual to the broader community, with most disaster triage guidelines using utilitarian principles aiming to provide the greatest benefit for the greatest number of people. ${ }^{[9]}$ The trade-off is that, unfortunately, some individuals who ordinarily would be offered ICU admission may no longer be prioritised when the demand for ICU admission exceeds capacity.

During a widespread disaster such as an infectious pandemic, it is necessary to continually balance individual and community needs and to make legally and ethically sound trade-offs as appropriate. The role of healthcare providers is to make decisions that can benefit community health while simultaneously respecting and considering an individual's interests. ${ }^{[10]}$ It is therefore unsurprising that questions about allocation of scarce resources lead to conflict and debate, ${ }^{[11]}$ and this is why it is important to have a publicly accessible guide that transparently outlines the policy and procedures for resource allocation. The CCSSA COVID-19 triage document ${ }^{[4]}$ was developed to form part of the comprehensive healthcare response to the COVID-19 pandemic in SA and should therefore not be considered in isolation. For elderly and other vulnerable groups, clear public health measures were put into place to minimise COVID19 infections, including to reduce the demand for tertiary-level healthcare for those high-risk groups.

Both the ConICTri and the CCSSA COVID-19 triage document ${ }^{[4,8]}$ conform to the accepted 'accountability for reasonableness' ethical framework for fair priority-setting: $:^{[12-15]}$ (i) during development and thereafter, the rationales for ICU prioritisation for both documents were transparent and publicly accessible online (publicity condition); (ii) the rationales and recommendations were developed through discussion and consensus by a multidisciplinary group of professionals, who determined them to be reasonable, relevant and appropriate to critical care practice in SA (relevance condition); (iii) an avenue exists for appealing and reviewing the guidelines through public debate and direct communication through the CCSSA secretariat (revisions/appeals condition); and (iv) the CCSSA structure ensures that the first three conditions are met (enforcement condition).

\section{Clinical considerations}

The CCSSA COVID-19 triage document follows what has been described as a 'soft utilitarian approach', where the main criteria for admission relate to function and comorbid conditions, and where priority is given to patients with the best chance of survival with acceptable quality of life and the most quality-adjusted lifeyears. ${ }^{[4,9,16]}$ Chronological age is a factor considered during triage decision-making, because advancing age (independent of the level of frailty) predisposes people to many life-limiting and life-threatening conditions and, significantly, is associated with an increased risk of poor ICU outcome, including mortality. ${ }^{[17]}$ Furthermore, elderly patients exhibit a weakened immune response to infections due to immunosenescence (an age-related decline in innate and adaptive immune response). This is likely to contribute to the significantly higher COVID-19-related mortality observed in elderly people. ${ }^{[9,18,19]}$ However, chronological age should not be the sole criterion for determining ICU admission, and this is certainly not advocated by the CCSSA. ${ }^{[4,8]}$ Bioethicists have argued that poor prognosis based on current and underlying disease should be the main allocation criterion for treatment during a crisis and, if advanced age correlates with this criterion, to use it as a prioritising factor should not be regarded as unfairly discriminatory. ${ }^{[20]}$ Under the guidance provided by the CCSSA COVID-19 triage document ${ }^{[4]}$ and other COVID19 triage recommendations, ${ }^{[21]}$ specific age criteria would only be applied where it is necessary to decide between people with equal (non-age-specific) ICU priority scores. For example, ICU admission of an elderly patient triaged to 'red' (highest priority) would take precedence over a younger patient triaged as 'orange' (intermediate priority). Age is never a comment on any individual's inherent worth or social value. but may serve as a measure of incremental ICU benefit by saving the most life-years. ${ }^{[21]}$

Erasmus $^{[6]}$ asserts that, if clinical assessment scores are used during prioritisation processes, the lungs ought to be excluded under COVID-19 triage conditions. Her rationale here is unclear. The triage guidelines presented in the CCSSA COVID-19 triage document ${ }^{[4]}$ are not specific to patients infected with SARSCoV-2, but apply equally to all patients presenting with critical illness during the pandemic crisis, consistent with international standards. ${ }^{[22]}$ Secondly, even if the document were only concerned with patients with COVID-19 disease, limiting triage criteria by excluding or targeting a specific organ system would not be appropriate, since COVID-19 is recognised as a multisystem disease. ${ }^{[23,24]}$ The Sequential Organ Failure Assessment (SOFA) score is simple, objective, uses routinely obtained measurements, and is considered to be an important adjunctive tool in the critical care domain. Furthermore, SOFA has repeatedly been demonstrated to be reliable and accurate in the ICU context as an indicator of disease severity and is a significant predictor of ICU mortality and other adverse outcomes. ${ }^{[17,25,26]}$

The other clinical assessment score recommended in the CCSSA COVID-19 triage document's prioritisation process ${ }^{[4]}$ is the Clinical Frailty Scale (CFS). Frailty is defined as a multidimensional syndrome characterised by a decline in physiological and cognitive reserve, which increases susceptibility to adverse events and poor outcome. ${ }^{[27]}$ There is currently no gold standard for diagnosing frailty. ${ }^{[28]}$ Although the term 'frailty' is most commonly associated with age, this syndrome has also been described in younger cohorts of patients admitted to ICUs. ${ }^{[29]}$ Increased frailty markers have been shown to be highly predictive of poor ICU outcome, including longer duration of ICU and hospital stay, increased post-discharge disability, and increased short- and longer-term mortality. ${ }^{[17,28,30,31]}$ 
The CFS was designed to holistically assess the presence and severity of frailty according to levels of physical activity, functional status, chronic illness burden and cognition. ${ }^{[28]}$ As such, disability (excluding long-term stable disabilities) and comorbidity, not age, are the explicit defining elements of frailty on the CFS. ${ }^{[28]}$ CFS scores between 1 and 3 are generally considered 'non-frail'; a score of 4 indicates a vulnerable or prefrail state; 5 is mildly frail; scores of 6 - 8 correspond with moderate to severe frailty; and a score of 9 indicates terminal illness. ${ }^{[28]}$ Erasmus $^{[6]}$ is mistaken when she states that 'mildly frail' individuals would be denied an ICU bed using the CCSSA COVID-19 triage document - the guidelines are explicit in stating that all individuals with a CFS $<6$ should move further in the priority-setting process. ${ }^{[4]}$ Furthermore, and perhaps missed by Erasmus, ${ }^{[6]}$ explicit guidance recommends that individuals who do not meet ICU admission priority owing to frailty should be offered an appropriate healthcare management plan outside the ICU, including palliative care where this is indicated. ${ }^{[4]}$ They are therefore not being denied access to healthcare, emergency or otherwise. Care is always afforded to patients.

The CFS is a well-established, robust and valid judgement-based assessment tool, frequently used in the ICU, based on information provided by the patient, family or medical records. ${ }^{[28,32-34]}$ We acknowledge that the CFS has not been locally validated and that the graphics used in the tool might be negatively slanted against the elderly. We therefore recommend that the CFS should be formally adapted and validated for use in the SA context, with appropriate public stakeholder input, to become more socially and culturally acceptable.

\section{Legal considerations}

SA has one of the most progressive constitutions in the world, in which human dignity and the right to life are non-derogable, even during a declared State of Emergency. The Constitution of the Republic of South Africa (1996) ${ }^{[35]}$ (in chapter 2 section 27(3)) states that one may not 'unfairly [our emphasis] discriminate directly or indirectly against anyone on one or more grounds, including race, gender, sex, pregnancy, marital status, ethnic or social origin, colour, sexual orientation, age, disability, religion, conscience, belief, culture, language and birth'. Section 27(5) states: 'Discrimination on one or more grounds ... is unfair unless it is established that the discrimination is fair. Erasmus ${ }^{[6]}$ asserts that the CCSSA triage documents are unfairly discriminatory against the elderly and therefore unconstitutional and unlawful. We strongly assert that the ICU triage guidelines are fair, rational, and both ethically and legally sound.

The landmark case to which Erasmus ${ }^{[6]}$ refers, Soobramoney $v$ Minister of Health, KwaZulu-Natal, provides implicit and explicit support for essential triage practice as a form of 'fair discrimination. ${ }^{[36]}$ The appellant (Soobramoney) suffered from chronic renal failure and other significant comorbidities and was denied repeated access to a public hospital's dialysis programme, based on the hospital's written triage policy. The appellant sought an order for access to dialysis treatment, based on his constitutional rights. The Court asserted that for use of scarce resources, the state must 'apply a holistic approach to the larger needs of society rather than to focus on specific needs of particular individuals within society' (paragraph 31). The judgment further explains that obligations imposed on the state regarding access to healthcare are dependent on available resources, and that corresponding rights may be limited by reason of lack of resources. The Court declared that it could not and would not interfere with decisions taken in good faith by medical authorities as to how to allocate budgets and decide on priorities. This was the first case in SA in which the Constitutional Court was asked to decide on the constitutional right to healthcare for everybody in the light of scarce resources in the healthcare system. The Court accepted that rationing of resources is integral to fair and reasonable health service delivery ${ }^{[36]}$

Erasmus $^{[6]}$ seems to interpret Soobramoney as asserting that emergency care at any level cannot ever be denied. This does not appear to be accurate, since the Constitutional Court held that the right to emergency medical treatment means that a person who suffers a sudden event that requires immediate medical attention should not be denied an ambulance or other available medical/ emergency services. ${ }^{[36]}$ We strongly support the view that all individuals should have access to emergency healthcare; this is not questioned in the CCSSA COVID-19 triage document. ${ }^{[4]}$ However, neither Soobramoney nor the Constitution indicates the level of medical care mandated by 'emergency care'. SECTION27, a public interest law centre that seeks to achieve equality and social justice in SA, states, "The right to health care does not mean that any person can demand and receive whatever type of health care they want. ${ }^{[37]}$ The Bill of Rights is not absolute, and the Constitution does not afford everyone the right to intensive and critical care in an ICU. The CCSSA COVID-19 triage document requires all patients to receive healthcare, at an appropriate level, including regular reassessment of their ICU triage status if indicated. ${ }^{[4]}$ Therefore, this document upholds individual rights to healthcare; it also ensures that decisions are not made arbitrarily, and, furthermore, that decisions taken are subject to revision if the individual's condition and/or ICU resource availability changes. Importantly, the scarcity of regional ICU resources determines which priority scores would qualify for ICU admission, and these are subject to change as demand and consumption increase or decrease. ${ }^{[4]}$

The Constitutional Court suggested there may be grounds for challenging rationing policies if they were unreasonable or if they were not applied fairly and reasonably. ${ }^{[3]}$ Justice Sachs stated that the rationing of access to life-prolonging resources is regarded as integral to, rather than incompatible with, a human rights approach to health care. He went on to state, 'while each claimant seeking access to public medical resources is entitled to individualized consideration, the lack of principled criteria for regulating such access could be more open to challenge than the existence and application of such criteria. ${ }^{[36]}$ To this end, publishing clear, simple and unambiguous triage guidelines, based on sound scientific and ethical principles, allows fair and consistent application of ICU triage across the country, provides decisional support in a time of crisis to improve performance and reduce moral distress, and prevents personal judgements based on the biases and prejudices of individual clinicians, as may occur when using the 'professional judgement' or gut instinct approach recommended by Erasmus. ${ }^{[6,8,21,22]}$ The use of appropriate, validated scoring systems further ensures consistency and fairness of application. Therefore, contrary to Erasmus's assertion $^{[6]}$ that triage committees are akin to 'death panels' and are designed to distance individual clinicians from the moral choices they are required to make, it is our assertion that clear guidelines, such as those produced by the CCSSA, ${ }^{[4]}$ along with accountability to a decision-making group, serve to protect the population from indiscriminate, potentially unsound, decision-making practice by healthcare providers. Another important point is that it should not be assumed that a patient not admitted to an ICU will certainly die. ${ }^{[38]}$ Triage committees are not choosing between a patient's life and death; they are assessing the probability of death v. survival (and quality 
of life) across a range of treatment options, which may or may not include critical care services.

Erasmus's assertion ${ }^{[6]}$ of political and social prejudice in healthcare, with 'selective care ... dispensed mainly for profit and at the expense of the socially vulnerable, ${ }^{\text {[5] }}$ is a broader sociopolitical problem in SA, but the CCSSA cannot be blamed for the inequality of healthcare access in this country. It is an unfortunate fact that the disproportionate majority of critical care in this country is still provided in private medical facilities, which are inaccessible to most of the SA population. ${ }^{[8]}$ This undoubtedly requires urgent redress.

The late Justice Madala stated, 'Some rights in the Constitution are the ideal and something to be strived for. They amount to a promise, in some cases, and an indication of what a democratic society aiming to salvage lost dignity, freedom and equality should embark upon. They are values which the Constitution seeks to provide, nurture and protect for a future South Africa. ${ }^{[36]}$ The CCSSA shares this ideal - a country where everyone who could benefit can access appropriate intensive care. Unfortunately, the current reality is different. SA does not have enough ICU beds, trained staff or equipment to meet the needs of our population. It is our sincere hope that the state fulfills its mandate to 'take reasonable ... measures, within its available resources, to achieve the progressive realization of each of these rights. $^{[36]}$ Until that realisation occurs, intensive care physicians must continue to use fair and consistent criteria to make difficult decisions about 'who gets the bed'.

\section{Declaration. None.}

\section{Acknowledgements. None.}

Author contributions. BM wrote the manuscript drafts, with input from all authors. All authors approved the final manuscript.

Funding. None.

Conflicts of interest. BMM, PDG, FP and IJ are sitting Council members of the CCSA. None of the authors have conflicts of interest to declare in respect of this submission.

1. Naidoo K, Singh J, Lalloo U. A critical analysis of ICU/HC beds in South Africa: 2008 - 2009. S Afr Med J 2013;103(10):751-753. https://doi.org/10.7196/SAMJ.6415

2. Bhagwanjee S, Scribante J. National audit of critical care resources in South Africa - unit and bed distribution. S Afr Med J 2007;97(12 Pt 3):1311-1314.

3. Basson A. Coronavirus: SA needs many more ICU beds to be ready for Covid-19 peaks, says Ramaphosa. News24, 31 May 2020. https://www.news24.com/news24/southafrica/news/coronavirus-sa-needs-manymore-icu-beds-to-be-ready-for-covid-19-peaks-says-ramaphosa-20200531 (accessed 15 October 2020).

4. Critical Care Society of Southern Africa. Allocation of scarce critical care resources during the COVID-19 pandemic health emergency in South Africa. 2020. https://criticalcare.org.za/covid-9/ (accessed 15 October 2020)

5. Christian MD. Triage. Crit Care Clin 2019;35(4):575-589. https://doi.org/10.1016/j.ccc.2019.06.009

6. Erasmus N. Age discrimination in critical care triage in South Africa: The law and the allocation of scarce health resources in the COVID-19 pandemic. S Afr Med J 2020;110(12):1172-1175. https://doi. scarce health resources in the COVID-19
org/10.7196/SAMJ.2020.v110i12.15344

7. MaX, Vervoort D. Critical care capacity during the COVID-19 pandemic: Global availability of intensive care beds. J Crit Care 2020;58:96-97. https://doi.org/10.1016/j.jcrc.2020.04.012

8. Joynt GM, Gopalan DP, Argent AA, et al. The Critical Care Society of Southern Africa Consensus Statement on ICU Triage and Rationing (ConICTri). S Afr Med J 2019;109(8b):613-269 and South Afr J Crit Care 2019;35(1b):53-65. https://doi.org/10.7196/SAMJ.2019.v109i8b.13947 and https://doi org/10.7196/SAJCC.2019.v35i1b.380
9. Jaziri R, Alnahdi S. Choosing which COVID-19 patient to save? The ethical triage and rationing dilemma. Ethics Med Public Health 2020;15:100570. https://doi.org/10.1016/j.jemep.2020.100570

10. Barnett DJ, Taylor HA, Hodge JG, et al. Resource allocation on the frontlines of public health preparedness and response: Report of a summit on legal and ethical issues. Public Health Rep 2009;124(2):295-303. https://doi.org/10.1177/003335490912400218

11. Hodge JG. Legal triage during public health emergencies and disasters. Adm Law Rev 2006;58(3):627-644.

12. Martin DK, Giacomini M, Singer PA. Fairness, accountability for reasonableness, and the views of priority setting decision-makers. Health Policy 2002;61(3):279-290. https://doi.org/10.1016/s0168$8510(01) 00237-8$

13. Daniels N. Accountability for reasonableness. BMJ 2000;321(7272):1300-1301. https://doi.org/10.1136/ bmj. 321.7272 .1300

14. Daniels N. Decisions about access to health care and accountability for reasonableness. J Urban Health 1999;76(2):176-191. https://doi.org/10.1007/BF02344674

15. Daniels N, Sabin JE. Accountability for reasonableness: An update. BMJ 2008;337:a1850. https://doi. org/10.1136/bmj.a1850

16. Clarfield AM, Dwolatzky T, Brill S, et al. Israel Ad Hoc COVID-19 Committee: Guidelines for care of older persons during a pandemic. J Am Geriatr Soc 2020;68(7):1370-1375. https://doi.org/10.1111/ jgs. 16554

17. So RKL, Bannard-Smith J, Subbe CP, et al. The association of clinical frailty with outcomes of patients reviewed by rapid response teams: An international prospective observational cohort study. Crit Care 2018;22(1):227. https://doi.org/10.1186/s13054-018-2136-4

18. Chiappelli F, Khakshooy A, Greenberg G. CoViD-19 immunopathology and immunotherapy. Bioinformation 2020;16(3):219-222. https://doi.org/10.6026/97320630016219

19. Cunha LL, Perazzio SF, Azzi J, et al. Remodeling of the immune response with aging: Immunosenescence and its potential impact on COVID-19 immune response. Front Immunol 2020;11:1748. https://doi. org/10.3389/fimmu. 2020.01748

20. Popescu D, Macoci A. Coronavirus: Allocating ICU beds and ventilators based on age is discriminatory. The Conversation, 22 April 2020. https://theconversation.com/coronavirus-allocating-icu-beds-andventilators-based-on-age-is-discriminatory-136459 (accessed 15 October 2020).

21. Sprung CL, Joynt GM, Christian MD, et al. Adult ICU triage during the coronavirus disease 2019 pandemic: Who will live and who will die? Recommendations to improve survival. Crit Care Med pandemic: Who will live and who will die? Recommendations to imp
2020;48(8):1196-1202. https://doi.org/10.1097/CCM.0000000000004410

22. Joebges S, Biller-Andorno N. Ethics guidelines on COVID-19 triage - an emerging international . Joebges S, Biller-Andorno N. Ethics guidelines on COVID-19 triage - an e
consensus. Crit Care 2020;24(1):201. https://doi.org/10.1186/s13054-020-02927-1

23. Zheng KI, Feng G, Liu WY, et al. Extrapulmonary complications of COVID-19: A multisystem disease? J Med Virol 2020 (epub 10 July 2020). https://doi.org/10.1002/jmv.26294

24. Garcia LF. Immune response, inflammation, and the clinical spectrum of COVID-19. Front Immunol 2020;11:1441. https://doi.org/10.3389/fimmu.2020.01441

25. Arts DG, de Keizer NF, Vroom MB, de Jonge E. Reliability and accuracy of Sequential Organ Failure Assessment (SOFA) scoring. Crit Care Med 2005;33(9):1988-1993. https://doi.org/10.1097/01. ccm.0000178178.02574.ab

26. De Grooth HJ, Geenen IL, Girbes AR, et al. SOFA and mortality endpoints in randomized controlled trials: A systematic review and meta-regression analysis. Crit Care 2017;21(1):38. https://doi.org/10.1186/ s13054-017-1609-1

27. Fried LP, Ferrucci L, Darer J, et al. Untangling the concepts of disability, frailty, and comorbidity: Implications for improved targeting and care. J Gerontol A Biol Sci Med Sci 2004;59(3):255-263. https:// doi.org/10.1093/gerona/59.3.m255

28. De Biasio JC, Mittel AM, Mueller AL, et al. Frailty in critical care medicine: A review. Anesth Analg De Biasio JC, Mittel AM, Mueller AL, et al. Frailty in critical care medi
2020;130(6):1462-1473. https://doi.org/10.1213/ANE.0000000000004665

29. Bagshaw M, Majumdar SR, Rolfson DB, et al. A prospective multicenter cohort study of frailty in younger Bagshaw M, Majumdar SR, Rolfson DB, et al. A prospective multicenter cohort study of frally
critically ill patients. Crit Care 2016;20(1):175. https://doi.org/10.1186/s13054-016-1338-x

30. Muscedere J, Waters B, Varambally A, et al. The impact of frailty on intensive care unit outcomes: A systematic review and meta-analysis. Intensive Care Med 2017;43(8):1105-1122. https://doi. org/10.1007/s00134-017-4867-0

31. Zampieri FG, Iwashyna TJ, Viglianti EM, et al. Association of frailty with short-term outcomes, organ support and resource use in critically ill patients. Intensive Care Med 2018;44(9):1512-1520. https://doi. org/10.1007/s00134-018-5342-2

32. Pugh RJ, Ellison A, Pye K, et al. Feasibility and reliability of frailty assessment in the critically ill: A systematic review. Crit Care 2018;22(1):49. https://doi.org/10.1186/s13054-018-1953-9

33. Hope AA, Hsieh SI, Petti A, et al. Assessing the usefulness and validity of frailty markers in critically ill adults. Ann Am Thorac Soc 2017;14(6):952-959. https://doi.org/10.1513/AnnalsATS.201607-538OC

34. Shears M, Takaoka A, Rochwerg B, et al. Assessing frailty in the intensive care unit: A reliability and 4. Shears M, Takaoka A, Rochwerg B, et al. Assessing frailty in the intensive care un
validity study. J Crit Care 2018;45:197-203. https://doi.org/10.1016/j.jcrc.2018.02.004

35. Constitution of the Republic of South Africa, Act 108 of 1996.17 th Amendment, 2012. https://www.gov, za/documents/constitution-republic-south-africa-1996 (accessed 15 October 2020).

36. Chaskalson P. Soobramoney v Minister of Health, KwaZulu-Natal: Full Judgement. 1997. http://www. 6. Chaskalson P. Soobramoney v Minister of Health, KwaZulu-Natal:
saflii.org/za/cases/ZACC/1997/17.html (accessed 23 October 2020).

37. Treatment Action Campaign and SECTION27. Standing up for our lives: A history of the access to medicines movement in South Africa. https://standingupforourlives.section27.org.za (accessed 12 October 2020).

38. Joynt GM, Gomersall CD, Tan P, Lee A, Cheng CA, Wong EL. Prospective evaluation of patients refused admission to an intensive care unit: Triage, futility and outcome. Intensive Care Med 2001;27(9):14591465. https://doi.org/10.1007/s001340101041

Accepted 28 October 2020 